\title{
Cumulative exposure to dust causes accelerated decline in lung function in tunnel workers
}

\author{
B Ulvestad, B Bakke, W Eduard, J Kongerud, M B Lund
}

\begin{abstract}
Objectives-To examine whether underground construction workers exposed to tunnelling pollutants over a follow up period of 8 years have an increased risk of decline in lung function and respiratory symptoms compared with reference subjects working outside the tunnel atmosphere, and relate the findings to job groups and cumulative exposure to dust and gases.
\end{abstract}

Methods-96 Tunnel workers and a reference group of 249 other heavy construction workers were examined in 1991 and re-examined in 1999. Exposure measurements were carried out to estimate personal cumulative exposure to total dust, respirable dust, $\alpha$-quartz, oil mist, and nitrogen dioxide. The subjects answered a questionnaire on respiratory symptoms and smoking habits, performed spirometry, and had chest radiographs taken. Radiological signs of silicosis were evaluated (International Labour Organisation (ILO) classification). Atopy was determined by a multiple radioallergosorbent test (RAST).

Results-The mean exposure to respirable dust and $\alpha$-quartz in tunnel workers varied from $1.2-3.6 \mathrm{mg} / \mathrm{m}^{3}$ (respirable dust) and $0.019-0.044 \mathrm{mg} / \mathrm{m}^{3}$ ( $\alpha$-quartz) depending on job task performed. Decrease in forced expiratory volume in 1 second $\left(\mathrm{FEV}_{1}\right)$ was associated with cumulative exposure to respirable dust $(p<0.001)$ and $\alpha$-quartz $(p=0.02)$. The multiple regression model predicted that in a worker 40 years of age, the annual decrease in $\mathrm{FEV}_{1}$ would be $25 \mathrm{ml}$ in a nonexposed non-smoker, $35 \mathrm{ml}$ in a nonexposed smoker, and 50-63 $\mathrm{ml}$ in a non-smoking tunnel worker (depending on job). Compared with the reference group the odds ratio for the occurrence of new respiratory symptoms during the follow up period was increased in the tunnel workers and associated with cumulative exposure to respirable dust.

Conclusions-Cumulative exposures to respirable dust and $\alpha$-quartz are the most important risk factors for airflow limitation in underground heavy construction workers, and cumulative exposure to respirable dust is the most important risk factor for respiratory symptoms. The finding of accelerated decline in lung function in tunnel workers suggests that better control of exposures is needed.

(Occup Environ Med 2001;58:663-669)
Keywords: heavy construction; respirable dust; lung function

Underground construction work is associated with health risks from various exposures, including dust, $\alpha$-quartz, oil mist, and nitrogen dioxide. ${ }^{1-6}$ Large amounts of dust and gases are liberated when a rock is blasted. Dust is also generated by rock drilling, spraying of concrete (shotcreting), and transport operations. Diesel powered machinery, which is used in most heavy construction work processes, produces carbon monoxide, oxides of nitrogen, various hydrocarbons, and particulate matter. Oil mist is produced when mineral oil is sprayed onto machinery for surface protection against concrete spills and onto concrete forms to prevent sticking by the concrete. A detailed description of exposure to dust and gas in tunnel construction work has previously been reported. ${ }^{7}$

Occupational exposure to $\alpha$-quartz may be an independent predictor of airflow limitation. ${ }^{89}$ Decreased lung function, increased incidence of airway inflammation, and bronchial hyperresponsiveness have been shown in subjects exposed to nitrogen dioxide ${ }^{10}{ }^{11}$ and oil mist. ${ }^{12}{ }^{13}$ In an earlier cross sectional survey we found that exposure to dust and gas in tunnel workers increased the occurrence of respiratory symptoms and airflow limitation compared with other heavy construction workers. ${ }^{14}$ However, the effects of exposure might have been biased by the cross sectional design of the study, as sensitive employees could have left the occupation and the workforce studied might be regarded as the survivors of the trade. The low prevalence of asthma in that study population $(<1 \%$ compared with about $6 \%$ in the general population) would support the presence of such a bias. The present report presents the results of a reinvestigation of the same cohort 8 years later. We hypothesised (a) that workers exposed to tunnelling pollutants would have higher risk of respiratory symptoms and increased decline in lung function than subjects who had worked outside the tunnels, and (b) that these findings would be related to job groups and differences in cumulative exposure to gases and dust during the 8 year period.

\section{Materials and methods}

JOB GROUPS

Tunnel workers were compared with a reference group comprising outdoor construction workers and white collar construction employees. The tunnel workers were further divided into two subgroups-drillers and shotcreters. The drillers perform conventional drill and blast operations, and shotcreters carry out the 
Table 18 Hour time weighted average exposures and cumulative exposures in heavy construction workers stratified by job group

\begin{tabular}{|c|c|c|c|c|c|c|c|c|c|c|c|c|}
\hline \multirow[b]{3}{*}{ Agent } & \multirow[b]{3}{*}{ Units } & \multirow[b]{3}{*}{$O E L$} & \multicolumn{6}{|c|}{ Tunnel workers } & \multicolumn{4}{|c|}{ Reference group } \\
\hline & & & \multicolumn{3}{|c|}{$\begin{array}{l}\text { Drillers } \\
(n t=52)\end{array}$} & \multicolumn{3}{|c|}{$\begin{array}{l}\text { Shotcreters } \\
(n t=14)\end{array}$} & \multicolumn{3}{|c|}{$\begin{array}{l}\text { Outdoor workers } \\
(n t=20)\end{array}$} & \multirow{2}{*}{$\begin{array}{l}\text { White collar } \\
\text { employees } \neq\end{array}$} \\
\hline & & & $n^{\star}$ & Mean & $S D$ & $n^{\star}$ & Mean & $S D$ & $n^{\star}$ & Mean & $S D$ & \\
\hline Total dust & $\mathrm{mg} / \mathrm{m}^{3}$ & 10 & 113 & 3.4 & 3.8 & 61 & 13.6 & 9.1 & 35 & 1.2 & 0.78 & 0.34 \\
\hline Respirable dust & $\mathrm{mg} / \mathrm{m}^{3}$ & 5 & 117 & 1.2 & 0.81 & 69 & 3.6 & 1.9 & 40 & 0.3 & 0.19 & 0.12 \\
\hline Cumulative exposure to respirable dust $\star \star$ & $\mathrm{mg} \cdot \mathrm{y} / \mathrm{m}^{3}$ & & & 9.6 & 0.2 & & 25.4 & 0.9 & & 2.1 & 0.1 & 0.9 \\
\hline$\alpha$-Quartz & $\mathrm{mg} / \mathrm{m}^{3}$ & 0.1 & 113 & 0.044 & 0.06 & 45 & 0.019 & 0.016 & 40 & 0.003 & 0.003 & 0.004 \\
\hline Cumulative exposure to $\alpha$-quartz $\star \star \star$ & mg.y/m $\mathrm{m}^{3}$ & & & 0.35 & 0.01 & & 0.13 & 0.01 & & 0.029 & 0.001 & 0.023 \\
\hline Oil mist & $\mathrm{mg} / \mathrm{m}^{3}$ & 1 & 79 & 0.35 & 0.21 & 23 & 0.55 & 0.59 & 16 & 0.18 & 0.23 & 0.04 \\
\hline Nitrogen dioxide & $\mathrm{ppm}$ & 25 & 39 & 0.78 & 0.69 & 15 & 0.6 & 0.5 & & I & & 0.08 \\
\hline
\end{tabular}

^Number of measurements.

†Number of workers participating in measurements.

$\ddagger$ Estimate.

$§$ Ceiling value.

INon-detectable, assumed to be ambient air concentrations, 10-20 ppb (Norwegian Institute for Air Research, Kjeller, Norway).

$\star \star$ Adjusted for sick leaves and other longer periods of absence.

OEL=Norwegian occupational exposure limits.

spraying of concrete on the tunnel walls. Outdoor construction workers perform iron fixing, shuttering, and concrete work. White collar construction employees carry out surveying and inspection, as well as ordinary office work. All subjects worked for 11 consecutive days and were off site for 10 days. According to an agreement between the employers and employees, the work shift was 10 hours with two breaks of 30 minutes each. A detailed description of the actual job groups has been reported previously. ${ }^{7}$

\section{OCCUPATIONAL EXPOSURE}

Between 1996 and 1999, personal exposure measurements of total dust, respirable dust, $\alpha$-quartz, oil mist, and nitrogen dioxide were carried out on 16 heavy construction sites.

A sample of workers from the three groups (drillers, shotcreters, and outdoor workers) was asked to participate in the exposure assessment. Participation was on a voluntary basis but all workers selected participated.

The sampling duration was 5-8 hours (unless otherwise noted) because of limited battery capacity of the sampling equipment and high dust load on the filters. The sampling time was considered representative of the whole workshift because the sampling periods within the shift were selected randomly and tasks were often repeated within the day. Measured exposure values were therefore used without further adjustment.

Total dust was collected on acrylic copolymer membrane filters (Versapore 800, Gelman Sciences, Ann Arbor, USA), with a $0.8 \mu \mathrm{m}$ pore size, fitted in $25 \mathrm{~mm}$ closed faced aerosol filter cassettes (Gelman Sciences, Ann Arbor, USA) at a sampling flow rate of $21 \mathrm{~min}^{-1}$. Respirable dust was collected on $37 \mathrm{~mm}$ cellulose acetate filters with a pore size of $0.8 \mu \mathrm{m}$ using a cyclone separator (Casella T13026/2, London, UK) at a sampling flow rate of $2.21 \mathrm{~min}^{-1}$. The $\alpha$-quartz content in the respirable dust sample was measured by $x$ ray diffraction.

Oil mist was collected on glass fibre filters (Whatman GF (A), Maidstone, England) with a back up filter of cellulose acetate with a pore size of $0.8 \mu \mathrm{m}$ in $37 \mathrm{~mm}$ closed faced aerosol cassettes (Millipore, Millipore Corporation, USA). The sampling time for oil mist was $2-4$ hours. Nitrogen dioxide was measured with direct reading electrochemical sensors with a data logging facility built into the instrument (Neotox-xl personal single-gas monitor, Neotronics Limited, Takeley, UK).

As neither tunnelling technology nor outdoor concrete construction technology have changed substantially since 1980 , the concentrations measured during the years 1996-9 were considered to be representative for exposure during the study period 1991-9. Cumulative historical exposure (before 1991) was also estimated based on the same measurements. The mean exposure of each agent in each job group was assigned to each worker within that group to estimate cumulative exposure. ${ }^{15}$ Also white collar construction employees were invariably somewhat exposed, for example during surveys and inspection work. Based on questioning and direct observations, we estimated that a white collar employee on average spent about 1 hour daily in the tunnel atmosphere. The exposure for the white collar employees was therefore estimated to be $1 / 10$ of the 8 hour time weighted averages measured in the drillers. The cumulative exposure figures were individually adjusted for sick leave and other longer periods of absence. Mean exposures were multiplied by the actual numbers of years (months) that each subject had worked within the 8 year study period. The mean exposure concentrations of all agents and the 8 year cumulative exposure to respirable dust and $\alpha$-quartz for each job group are shown in table 1 .

SELECTION OF SUBJECTS AND STUDY DESIGN The design was longitudinal with a fixed cohort. The first examination was carried out in 1991. All subjects $(n=417)$ were recruited from Norway's major construction company. The index group comprised all tunnel workers ( $n=122,104$ drillers and 18 shotcreters) employed by the company at that time. Recruited as a reference group were all outdoor construction workers (shutters and iron fixers, $\mathrm{n}=205$ ), and all white collar construction employees (engineers and foremen, $n=90$ ) employed at the same construction sites as the tunnel workers. All medical tests were carried out at the work sites. 
From the original cohort $(n=417), 345$ subjects $(83 \%)$ participated in a follow up study in 1999. Subjects aged 55 years or older in 1991 $(n=20)$ were excluded. The limitation in age was set because employees are offered early retirement at the age of 63. Also excluded from the follow up study were subjects who had asthma or chronic obstructive pulmonary disease (COPD) diagnosed by a physician in 1991 (13 tunnel workers and two outdoor workers). Lost to follow up were 37 subjects: two had died in work accidents, two had left work due to disability (non-respiratory causes), five had changed to other occupations, and 28 declined to participate. These 28 subjects (four drillers, five outdoor workers, and 19 white collar employees) were in 1991 comparable with the index group for mean age (41 $v 39$ years), duration of employment (16 $v 15$ years), smoking habits (current smokers $48 \%$ v $49 \%$ ) and forced expiratory volume in 1 second $\left(\mathrm{FEV}_{1}, 101 \% v 101 \%\right.$ of predicted), and there is no reason to think that their absence should bias the results. Thus, in 1999 the study population comprised 96 tunnel workers, 178 outdoor workers, and 71 white collar employees. The medical tests were carried out at the health service office, after the workers had had at least 1 week off. The study was approved by the data national inspectorate and the regional medical ethics committee.

\section{QUESTIONNAIRE}

A self administered questionnaire applied in earlier investigations ${ }^{16}$ and validated in $1989,{ }^{18}$ was used to assess the presence of lower airways symptoms at both times of examination. The questionnaire included questions on asthma diagnosed by a physician, occurrence of cough, wheeze, chest tightness, and shortness of breath (at rest and at exertion). In accordance with diagnostic criteria previously applied in population surveys, COPD was diagnosed in those with a history of chronic cough, phlegm when coughing, breathlessness or wheezing, and a ratio of $\mathrm{FEV}_{1} /$ forced vital capacity (FVC) of less than $0.7 .{ }^{19}$ To categorise smoking, the subjects were classified as never smokers, former smokers, and current smokers. Former smokers were those who had stopped smoking more than 12 months ago. Cumulative exposure to tobacco smoke was measured in pack-years, both in current smokers and in former smokers. ${ }^{8}$

\section{SPIROMETRY}

Spirometric measurements were performed in the sitting position with a bellow spirometer (Vitalograph S with PFT2 PLUS printer, Buckingham, UK), operated by the same two trained and experienced technicians in 1991 and 1999. The spirometer was calibrated daily by a 31 syringe. The subjects were wearing a nose clip during the test. The measurements were performed in accordance with the guidelines recommended by the American Thoracic Society in $1987 .{ }^{20}$ Room and spirometer temperature, as well as barometric pressure, were recorded. Each subject performed at least three FVC curves with a maximum variation of
$50 \mathrm{ml}$ or $2 \%$. Recorded variables were FVC, $\mathrm{FEV}_{1}, \mathrm{FEV}_{1} / \mathrm{FVCx}_{100}\left(\mathrm{FEV}_{1} \%\right)$ and forced expiratory flow from $25 \%-75 \%$ of $\mathrm{FVC}$ $\left(\mathrm{FEF}_{25 \%-75 \%}\right)$. The lung function variables were expressed in absolute values and as percentage of predicted, using the reference values of the European Coal and Steel Community (ECSC). ${ }^{21}$

\section{IgE MEASUREMENTS}

Venous blood samples were taken from all subjects at the start of the survey (1991). The serum samples were frozen at $-70^{\circ} \mathrm{C}$. Screening for atopic allergy was done with Phadiatop (Pharmacia Diagnostics AB, Uppsala, Sweden), a multiple radioallergosorbent test (RAST) of IgE against nine common respiratory allergens (birch, timothy, mugwort, Cladosporium herbarum, Alternaria tenuis, Dermatophagoides pteronyssinus, cat dander, dog epithelium, and horse dander ${ }^{22}$ ). Atopy was defined as having a positive Phadiatop test.

\section{CHEST RADIOGRAPHS}

All tunnel workers had full format chest radiographs taken both in 1991 and 1999. The radiographs were read blind by two independent radiologists. The first reader was the radiologist at the hospital where the chest radiographs were taken. The second reader was a certified International Labour Organisation (ILO) A reader, who used the ILO classification method to evaluate radiological signs of silicosis. ${ }^{23}$ Chest radiographs were taken to detect potential cases of silicosis. As silicosis was not expected to occur in the reference subjects, radiographs were omitted for ethical reasons.

\section{STATISTICAL ANALYSIS}

Demographic data were summarised for each job category, with mean (SD) for continuous data, and $n(\%)$ for categorical data. The relation between changes in lung function $(\triangle \mathrm{FVC}$, $\Delta \mathrm{FEV}_{1}$, and $\left.\Delta \mathrm{FEF}_{25 \%-75 \%}\right)$ and the covariates job group, pack-years of tobacco estimated in 1999, age, and atopy were investigated by multiple linear regression. The mean exposure of each agent (total dust, respirable dust, $\alpha$-quartz, nitrogen dioxide, and oil mist) in each job group was assigned to each worker within that group to estimate cumulative exposure. ${ }^{15}$ Both historical exposure (before 1991) and cumulative exposure for the follow up period (1991-9) were estimated. Cumulative exposure for the follow up period was adjusted for sick leave over 2 months and other longer periods of absence. Spearman's correlation coefficients $\left(r_{s}\right)$ were calculated to evaluate correlations between independent exposure variables. The cumulative exposure to respirable dust during the follow up period was strongly correlated with the cumulative exposure to total dust $\left(r_{s}=0.97\right)$, nitrogen dioxide $\left(r_{s}=0.82\right)$, and oil mist $\left(r_{s}=0.77\right)$, and cumulative exposure to $\alpha$-quartz was correlated with nitrogen dioxide $\left(r_{s}=0.95\right)$. Cumulative exposures to respirable dust and $\alpha$-quartz were not strongly correlated $\left(r_{s}=0.47\right)$. In the univariate analysis, cumulative exposure to oil was not a significant 
Table 2 Characteristics of 345 heavy construction workers by job group at the start of the survey (1991)

\begin{tabular}{lrcr}
\hline & $\begin{array}{c}\text { Tunnel } \\
\text { workers } \\
(n=96)\end{array}$ & $\begin{array}{l}\text { Outdoor } \\
\text { workers } \\
(n=178)\end{array}$ & $\begin{array}{c}\text { White collar } \\
\text { employees } \\
(n=71)\end{array}$ \\
Variable & $39(9)$ & $39(10)$ & $41(8)$ \\
Age (y, mean (SD)) & $180(6)$ & $179(6)$ & $180(6)$ \\
Height (cm, mean (SD)) & $19(8)$ & $16(8)$ & $18(9)$ \\
Duration of employment (y, mean (SD)) & $26(27)$ & $51(29)$ & $29(41)$ \\
Smoking (n (\%)): & $20(21)$ & $34(19)$ & $20(28)$ \\
$\quad$ Never smokers & $50(52)$ & $93(52)$ & $22(31)$ \\
$\quad$ Former smokers & $10(12)$ & $14(8)$ & $16(12)$ \\
$\quad$ Current smokers & $12(13)$ & $27(15)$ & $15(21)$ \\
Phadiatop positive (n (\%)) & & &
\end{tabular}

variable $(p=0.9)$, and was therefore excluded from the multiple linear regression model. Cumulative exposure to nitrogen dioxide was a significant variable when tested alone $(p=0.01)$, but not when combined with the variables cumulative exposure to $\alpha$-quartz or respirable dust. When nitrogen dioxide was included in the multiple linear regression model, $R^{2}$ dropped from 0.15 to 0.03 , thus disturbing the fit of the model. The variable was therefore excluded from the final explanatory analyses. Estimated changes in $\mathrm{FEV}_{1}$ with age, smoking, and cumulative exposures as explanatory variables were predicted from the regression equation:

$\Delta \mathrm{FEV}_{1}=\mathrm{C}+\mathrm{C} 1^{\star}$ age $+\mathrm{C} 2{ }^{\star}$ smoking +

$\mathrm{C} 3^{\star}$ cumulative exposure respirable dust +

$\mathrm{C} 4{ }^{\star}$ cumulative exposure $\alpha$-quartz.

As we had carried out specific measurements of exposures, the "surrogate" variable duration of employment was not included in the final regression model.

The relation between the occurrence of new respiratory symptoms (yes/no) during the follow up period and the covariates job group (tunnel or reference), smoking (non-smoker, former smoker, or current smoker), age, and atopic allergy (yes or no) was investigated by means of logistic regression. A model with respirable dust was also tested. Atopy had no influence on the models. Statistical analyses were carried out with SYSTAT 9.0 and SPSS 9.0 (SPSS, Chicago, IL, USA).

\section{Results}

CHARACTERISTICS OF THE STUDY POPULATION Characteristics of the study population according to job group are given in table 2. There were no significant differences between the tunnel workers and the two reference populations for age, height, atopy, and duration of employment. Compared with the white collar employees, the proportions of current smokers were higher in the tunnel workers and the outdoor workers.

\section{CHANGES IN LUNG FUNCTION ASSOCIATED WITH} JOB GROUPS

At the start of the survey there were no significant differences in lung function data across job groups (drillers, shotcreters, outdoor workers, or white collar employees). Mean values for $\mathrm{FVC}$ and $\mathrm{FEV}_{1}$ were above $100 \%$ predicted for all job groups. Over the 8 year follow up period, the outdoor workers and white collar employees did not have different lung function changes, and the two groups were therefore merged into one reference group.

Compared with the reference group, and adjusting for age and smoking (pack-years), the drillers had a significantly larger decrease in $\mathrm{FEV}_{1}$, and the shotcreters a larger decrease in both $\mathrm{FEV}_{1}$ and $\mathrm{FEF}_{25-75 \%}$ (table 3).

\section{LUNG FUNCTION CHANGES ASSOCIATED WITH}

CUMULATIVE EXPOSURE

There were no associations between the historical (up to 1991) cumulative exposures to tunnelling pollutants and decreases in lung function. During the 8 year follow up period, after adjustment for age and current smoking, the decrease in $\mathrm{FEV}_{1}$ was associated with cumulative exposure to respirable dust $(p<0.001)$ and $\alpha$-quartz $(p=0.02$, table 4$)$. The regression model predicts that in a worker 40 years of age, the annual decline in $\mathrm{FEV}_{1}$ in a non-exposed non-smoker would be $25 \mathrm{ml}$, in a non-exposed smoker $35 \mathrm{ml}$, in a non-smoking driller $50 \mathrm{ml}$, and in a non-smoking shotcreter $63 \mathrm{ml}$. The reduction in $\mathrm{FEF}_{25 \%-75 \%}$ over the same 8 year period was associated with cumulative exposure to respirable dust $(p=0.01)$ (table 4), while reduction in FVC was not related to cumulative exposure.

\section{RESPIRATORY SYMPTOMS}

Compared with the reference group, and after adjustment for age and current smoking, the odds ratios for new respiratory symptoms (any respiratory symptom, morning cough, cough during the day, shortness of breath on exercise, attacks of dyspnoea and wheezing) were increased in the tunnel workers (table 5). Respiratory symptoms were associated with cumulative exposure to respirable dust (table 5), but not with $\alpha$-quartz. Non-significant differences in symptoms between the groups are not

Table 3 Lung function in each job category, and lung function changes after 8 years of work

\begin{tabular}{|c|c|c|c|c|c|c|c|c|c|}
\hline \multirow[b]{3}{*}{ Lung function (l) } & \multicolumn{6}{|c|}{ Tunnel workers $(n=96)$} & & & \\
\hline & \multicolumn{3}{|c|}{ Drillers $(n=79)$} & \multicolumn{3}{|c|}{ Shotcreters $(n=17)$} & \multicolumn{3}{|c|}{ Reference group $(n=249)$} \\
\hline & Mean & $S E$ & $\%$ Predicted & Mean & $S E$ & $\%$ Predicted & Mean & $S E$ & $\%$ Predicted \\
\hline FVC (1991) & 5.4 & 0.09 & 106 & 5.6 & 0.2 & 107 & 5.3 & 0.07 & 105 \\
\hline$\triangle \mathrm{FVC}(1991-9)$ & 0.24 & 0.2 & & 0.34 & 0.4 & & 0.25 & 0.02 & \\
\hline $\mathrm{FEV}_{1}(1991)$ & 4.2 & 0.08 & 101 & 4.5 & 0.2 & 103 & 4.1 & 0.05 & 101 \\
\hline$\Delta \mathrm{FEV}_{1}(1991-9)$ & $0.43^{\star}$ & 0.04 & & $0.54 \dagger$ & 0.1 & & $0.26^{\star} \dagger$ & 0.02 & \\
\hline $\mathrm{FEF}_{25-75 \%}(1991)$ & 3.8 & 0.1 & 84 & 4.2 & 0.3 & 87 & 3.8 & 0.09 & 86 \\
\hline$\Delta \mathrm{FEF}_{25-75 \%}(1991-9)$ & 0.59 & 0.06 & & $0.97 \ddagger$ & 0.3 & & $0.40 \ddagger$ & 0.06 & \\
\hline
\end{tabular}

${ }^{\star} \dagger \mathrm{p}<0.001, \neq \mathrm{p}=0.006$. Pairs of significantly different means between job categories, adjusted for age and smoking (pack-years) in multiple linear regression models. $\star=$ drillers $v$ reference group; $\dagger=$ shotcreters $v$ reference group; $\ddagger=$ shotcreters $v$ reference group. 
Table 4 Multiple linear regression model for $\triangle F E V_{1}(\mathrm{ml})$ and $\triangle F E F_{25-75 \%}(\mathrm{ml})$ during the follow up period in 345 heavy construction workers

\begin{tabular}{|c|c|c|c|c|c|c|}
\hline \multirow[b]{2}{*}{ Covariables } & \multicolumn{3}{|c|}{$\begin{array}{l}\triangle F E V_{1}(\mathrm{ml}) \text { in all workers } \\
\left(R_{\text {adjusted }}^{2}=0.15\right)\end{array}$} & \multicolumn{3}{|c|}{$\begin{array}{l}\Delta F E F_{25-75 \%}(\mathrm{ml}) \text { in all workers } \\
\left(R_{\text {adjusted }}^{2}=0.06\right)\end{array}$} \\
\hline & $\begin{array}{l}\text { Regression } \\
\text { coefficient }\end{array}$ & $S E$ & $p$ Value & $\begin{array}{l}\text { Regression } \\
\text { coefficient }\end{array}$ & $S E$ & p Value \\
\hline Constant & 53 & 61 & 0.39 & 404 & 191 & 0.04 \\
\hline Age $(y)$ & 3.6 & 1.4 & 0.01 & -3.7 & 4.5 & 0.4 \\
\hline Current smoking & 80 & 26 & 0.002 & 219 & 81 & 0.007 \\
\hline Cumulative exposure to respirable dust (mg.y/m $\mathrm{m}^{3}$ ) & 10.6 & 2.8 & $<0.001$ & 23.6 & 9 & 0.009 \\
\hline Cumulative exposure to $\alpha$-quartz (mg.y/m $/ \mathrm{m}^{3}$ ) & 271 & 121 & 0.02 & -30.4 & 380 & 0.9 \\
\hline
\end{tabular}

Table 5 Odds ratio (OR) for new symptoms during the follow up period stratified by job group (tunnel/reference group) in 345 heavy construction workers, and related to cumulative exposure to respirable dust

\begin{tabular}{|c|c|c|c|c|c|}
\hline \multirow[b]{2}{*}{ Symptoms } & \multicolumn{2}{|c|}{$\begin{array}{l}\text { Tunnel workers } \\
(n=96)\end{array}$} & \multicolumn{2}{|c|}{$\begin{array}{l}\text { Reference group } \\
(n=249)\end{array}$} & \multirow[b]{2}{*}{$\begin{array}{l}\text { Respirable dust } \\
\text { OR }(95 \% \text { CI) }\end{array}$} \\
\hline & $\begin{array}{l}\text { New cases } \\
(1991-9) n\end{array}$ & $\begin{array}{l}O R^{*} \\
(95 \% C I)\end{array}$ & $n$ & $O R$ & \\
\hline Any respiratory symptom & 44 & $3.8(2.3$ to 6.4$)$ & 45 & 1 & 2.9 (1.9 to 4.5$)$ \\
\hline Morning cough & 14 & $3.9(1.7$ to 9.3$)$ & 10 & 1 & $2.7(1.7$ to 4.5$)$ \\
\hline Cough during the day & 21 & $6.7(2.9$ to 15$)$ & 10 & 1 & $4.5(2.8$ to 7.4$)$ \\
\hline Shortness of breath on exercise & 11 & $6.2(2.1$ to 18$)$ & 5 & 1 & $3.5(2.0$ to 6.1$)$ \\
\hline Attacks of dyspnoea & 7 & $20.2(2.4$ to 170$)$ & 1 & 1 & $9.1(3.8$ to 22$)$ \\
\hline Chest wheezing & 10 & $9.3(2.5$ to 35$)$ & 3 & 1 & $3.6(2.0$ to 6.5$)$ \\
\hline
\end{tabular}

${ }^{\star} \mathrm{OR}$ adjusted for age and current smoking by logistic regression.

†Per unit $\left(10 \mathrm{mg} \cdot \mathrm{y} / \mathrm{m}^{3}\right)$.

presented in table 5. Three workers (all shotcreters) developed asthma during the follow up period.

CHEST RADIOGRAPHS

None of the tunnel workers had radiographic signs of pneumoconiosis. At the start of the survey, one worker had signs of pleura plaques. There were no cases with new radiographic findings during the follow up period. The readers agreed in their findings.

\section{Discussion}

In this longitudinal study of heavy construction workers, we investigated the effects of exposure to gas and dust on lung function. Our main findings were that $(a)$ the decrease in $\mathrm{FEV}_{1}$ across job groups was associated with cumulative exposure to respirable dust and $\alpha$-quartz, and $(b)$ tunnel workers had an increased decline in $\mathrm{FEV}_{1}$, compared both with outdoor workers and white collar employees. The occurrence of new respiratory symptoms during the 8 year follow up was also increased in the tunnel workers, and associated with cumulative exposure to respirable dust.

The annual decrease in $\mathrm{FEV}_{1}$ in nonexposed non-smokers was estimated to be 25 $\mathrm{ml}$, which corresponds with the predicted, physiological decline. ${ }^{21}$ Smokers had an excess yearly decrease of $10 \mathrm{ml}$, which is in line with cross sectional data in South African gold miners who smoke $(7 \mathrm{ml} / \text { year })^{24}$ and longitudinal data in United States men (12.6 ml/year). ${ }^{25}$

The excess annual decline in $\mathrm{FEV}_{1}$ in non-smoking tunnel workers (drillers) was estimated to be $25 \mathrm{ml}$ ( $38 \mathrm{ml}$ in shotcreters), compared with $17 \mathrm{ml}$ found in our previously reported cross sectional study. ${ }^{14}$ A healthy worker effect and selective survival most likely explain the discrepancy between the findings. In cross sectional surveys, sensitive employees will often have left the occupation and the workforce studied will comprise the survivors in the trade. In the present longitudinal study, $83 \%$ of the original cohort was re-examined.

The accelerated decline in $\mathrm{FEV}_{1}$ in tunnel workers was higher than that reported in South African gold miners $(9 \mathrm{ml} / \mathrm{year})^{24}$ and British coal miners $\left(7 \mathrm{ml} /\right.$ year). ${ }^{26}$ This difference may partly be explained by the difference between longitudinal and cross sectional designs. However, differences in ventilation efficiency may be another possible reason why exposure in tunnel work might be more detrimental to the airways than exposure in mines. Although mines are permanent work sites with sufficient time to plan and improve the ventilation system, tunnels are ambulant work places with ambulant and temporary ventilation. Thus ventilation may be better in mines than in tunnels.

The absence of radiological pathology in the tunnel workers excludes the possibility that the accelerated decline in $\mathrm{FEV}_{1}$ was caused by silicosis. This is in line with the findings of Malmberg et al, who found that granite crushers tended to develop airways obstruction rather than restrictive function loss and fibrosis as found in silicosis. ${ }^{9}$

Neither changes in lung function nor new respiratory symptoms during the follow up period were associated with estimates of previous (presurvey) cumulative exposure. This was expected as workers who had asthma and COPD diagnosed at the first examination were excluded from the follow up investigation.

As correlations between cumulative exposure to total dust, respirable dust, $\alpha$-quartz, nitrogen dioxide, and oil mist were high, it is difficult to distinguish between the various tunnelling pollutants and the detrimental effects on the airways. We chose to select respirable dust and $\alpha$-quartz for the final statistical analyses. Both have been documented to cause chronic airflow limitation in previous 
studies. ${ }^{278}$ None the less, we realise that the changes in lung function could be associated also with exposures other than respirable dust and $\alpha$-quartz.

Both nitrogen dioxide and oil mist may cause adverse effects on the airways. ${ }^{10-13}$ In healthy subjects, exposure to $2 \mathrm{ppm}$ nitrogen dioxide for 4 hours has been shown to cause neutrophilic inflammation in the airways. ${ }^{10}$ In our study, mean exposure to nitrogen dioxide was moderate $(0.8 \mathrm{ppm})$ compared with the national occupational ceiling value $(2 \mathrm{ppm})$. However, we cannot rule out that short term high exposures to nitrogen dioxide have occurred, for example when passing through the blast cloud, and that such peak exposures may have contributed to the accelerated lung function decline found in the tunnel workers. In a previous study we found that tunnel workers who used a special type of explosive showed a temporary decline in lung function, most likely caused by peak exposures to nitrogen dioxide. ${ }^{28}$ In an experimental study, repeated exposures to nitrogen dioxide have been shown to induce neutrophilic inflammation in the lower airways. ${ }^{11}$ These studies support the hypothesis that peak exposures to nitrogen dioxide may be associated with chronic loss of lung function.

Oil mist was also measured at moderate concentrations (less than one third of the occupational exposure limit (OEL)), but may none the less have had an adverse effect on lung function. The regression coefficients found for respirable dust and $\alpha$-quartz are therefore probably too high as estimates of the effect of these components alone.

Three shotcreters developed asthma during the follow up period. Significant increase in airway resistance and decreases in flow volume variables $\left(\mathrm{FVC}, \mathrm{FEV}_{1}\right.$, and $\mathrm{MEF}_{75 \%}$ ) have been shown in British shotcreting operators after one work shift. ${ }^{29}$ The reported changes were correlated with exposure to dust, whereas smoking had no influence..$^{29}$ In our study, mean exposures to total dust and respirable dust were significantly higher in shotcreters than in drillers $\left(13.6 v 3.4 \mathrm{mg} / \mathrm{m}^{3}\right.$ and $\left.3.6 v 1.2 \mathrm{mg} / \mathrm{m}^{3}\right)$, and high also when compared with the OELs $\left(10 \mathrm{mg} / \mathrm{m}^{3}\right.$ and $5 \mathrm{mg} / \mathrm{m}^{3}$ respectively). Exposure to $\alpha$-quartz was comparable between drillers and shotcreters. It could be speculated that the overload exposure to dust in shotcreting might contribute to an increased risk of asthma. However, the number of subjects is small and the three cases of asthma may be unrelated to occupational exposure.

The workers were divided into job groups based on the type of job they held in 1991. The assumption was made that the mean exposure of the respective job groups represented the mean exposure concentration for each individual worker during the 8 years of follow up. Even though we aimed at obtaining correct exposure classification in all subjects, some degree of misclassification may have occurred as the exposure assessment was based on occupational group measurements instead of individual measurements. It is possible that some drillers might have carried out shotcreting for short periods, resulting in a higher exposure to respirable dust than assigned. As drillers perform a craft that requires special training and certification, no crossover from the other job categories to drilling is expected.

Some misclassification of the exposure variable might have occurred because quantitative data on historical exposure were not available. Our estimates of exposure before the survey were based on the assumption that the excavation technology and type of machinery used had not changed substantially since around 1980. The change from rail transport (electrical) to diesel powered articulated trucks took place in the early 1970s, and hydraulic drills replaced pneumatic drills during the period 1975-80. Since 1980 no major changes have taken place in Norwegian tunnelling technology.

Confounding from previous exposure in jobs other than heavy construction was considered unlikely. In Norway, a career in heavy construction is often a family tradition. The workers usually come from rural areas. They enter the trade after leaving school and train to become skilled workmen when they are in their early twenties. Generally they stay in the trade until retirement.

Potential limitations of the study would be selection mechanisms, such as the healthy worker effect and selective survival. These would typically result in an underestimate of the association between exposure and lung function decline. Smoking homogeneity is a common feature in occupational cohorts ${ }^{30}$ and is associated with uniform lifestyle and social class. Typically, in our study, smoking was most common among the most heavily exposed workers. About $50 \%$ of the tunnel workers and outdoor workers were current smokers, compared with about $30 \%$ of the white collar employees.

At the start of the survey (1991), lung function tests were carried out at the work sites after the workers had started their work period. In 1999, lung function testing was performed at the health service office after at least 1 week off. This difference may introduce an error, as a short term decrease in lung function might have occurred at the first examination. This, however, would most likely have contributed to underestimate any long term changes.

In recent years the potential harmful effect of exposure to diesel exhaust particles has become a subject of major concern. ${ }^{31}{ }^{32}$ As diesel powered equipment is commonly used at all underground construction sites, diesel exposure may have contributed to the decline in lung function found in the tunnel workers. At one of our tunnel sites, the concentration of elemental carbon was measured as a marker of diesel exhaust. The geometric group mean exposure ranged from 100 to $340 \mu \mathrm{g} / \mathrm{m}^{3},{ }^{7}$ which is slightly higher than that reported from measurements in a potash mine (group means ranged from 53 to $345 \mu \mathrm{g} / \mathrm{m}^{3}$ ). ${ }^{33}$ To our knowledge, no countries have specific regulations on diesel exhaust emissions. 
We conclude that cumulative exposures to respirable dust and $\alpha$-quartz are major risk factors for airflow limitation in underground heavy construction workers. Exposure to respirable dust is the most important risk factor for respiratory symptoms. Other exposures correlated with respirable dust or $\alpha$-quartzsuch as oil mist and nitrogen dioxide-may also contribute to decline in lung function. The finding of adverse pulmonary effects related to exposure in underground construction work call for better technological solutions to prevent exposure.

We thank the workers for participating in the study, Dr Arne Borgersen, Majorstua Radiological Institute, Oslo, Norway for carrying out the ILO classification, and MSc Per Fuglerud, Parexel Medstat, Norway for statistical assistance. The project received financial support from the Working Environment Fund of the Confederation of Norwegian Business and Industry.

1 Bavley $\mathrm{H}$. Some environmental aspects in the construction of the city tunnel. Ind Hyg Quarterly 1950;11:125-9.

2 Burns C, Ottoboni F, Mitchell HW. Health hazard and heavy construction. Ind Hyg f 1962;23:273-81.

3 Sullivan PA, Bang KM, Hearl FJ, et al. Respiratory disease risks in the construction industry. Occup Med 1995;10:313risks

4 Ringen K, Seegal J, Englund A. Safety and health in the construction industry. Ann Rev Public Health 1995;16:16588 .

5 Wong PH, Phoon WH, Tan KT. Industrial hygiene aspects of tunneling work for the mass rapid transit system in Sinof tunneling work for the mass rapid
gapore. Appl Ind Hyg 1988;3:240-3.

6 Petersen JS, Zwerling C. Comparison of health outcomes among older construction and blue-collar employees in the United States. Am F Ind Med 1998;24:280-7.

7 Bakke B, Stewart P, Ulvestad B, et al. Dust and gas exposure in tunnel construction work. Am Ind Hyg Assoc f (in press).

8 Humerfelt S, Eide GE, Gulsvik A. Association of years of occupational quartz exposure with spirometric airflow limitation in Norwegian men aged $30-46$ years. Thorax 1998;53:649-55.

9 Malmberg P, Hedenstroem H, Sundblad BM. Changes in lung function of granite crushers exposed to moderately high silica concentrations: a 12 year follow up. Brf Ind Med 1993;50:726-31.

10 Blomberg A, Krishna MT, Bocchino V, et al. The inflammatory effects of $2 \mathrm{ppm} \mathrm{NO}_{2}$ on the airways of healthy tory effects of $2 \mathrm{ppm} \mathrm{NO}_{2}$ on the airways of healthy
subjects. Am $\mathcal{F}$ Respir Crit Care Med 1997;156:418-24.

11 Blomberg A, Krishna MT, Helleday R, et al. Persistent airway inflammation but accommodated antioxidant and lung function responses after repeated daily exposure to lung function responses after repeated daily exposure to nitroge

12 Svendsen K, Hilt B. Lung function disturbances and chest $x$ ray abnormalities among marine engineers. Am f Ind $\mathrm{Med}$ 1999;35:590-94.
13 Massin N, Bohadana AB, Wild P, et al. Airway responsiveness, respiratory symptoms, and exposures to soluble oil mist in mechanical workers. Occup Environ Med 1996;53: $748-52$

14 Ulvestad B, Bakke B, Melbostad E, et al. Increased risk of obstructive pulmonary disease in tunnel workers. Thorax 2000;55:277-82.

15 Rappaport SM. Selection of the measures of exposure for epidemiology studies. Appl Occup Environ Hyg 1991;6:44857.

16 Kongerud J, Groennesby JK, Magnus P. Respiratory symptoms and lung function of aluminium potroom workers. Scand $\mathcal{F}$ Work Environ Health 1990;16:270-7.

17 Melbostad E, Eduard W, Magnus P. Chronic bronchitis in farmers. Scand f Work Environ Health 1997;23:271-80.

18 Kongerud J, Vale JR, Aalen OO. Questionnaire reliability and validity for aluminium potroom workers. Scand $\mathcal{F}$ Work Environ Health 1989;15:364-70.

19 Bakke P, Baste V, Hanoa R, et al. Prevalence of obstructive lung disease in a general population: relation to occupaional title and exposure to some airborne agents. Thorax 1991;46:863-70.

20 American Thoracic Society. Standardization of spirometry: 1987 update. Am Rev Respir Dis 1987;136:1285-98.

21 Quanjar PH, Tammeling GJ, Cotes JE. Standardized lung function testing. Eur Respir F 1993;10:1683-93.

22 Eriksson NE. Allergy screening with Phadiatop and CAP Phadiatop in combination with a questionnaire in adults with asthma and rhinitis. Allergy 1990;45:285-92.

23 International Labour Office. Guidelines for the use of ILO international classification of radiographs of pneumoconiosis, revised ed. Geneva: ILO, 1980.

24 Cowie RL, Mabena SK. Silicosis, chronic airflow limitation, and chronic bronchitis in South African gold miners. Am Rev Respir Dis 1991;143:80-4.

$25 \mathrm{Xu} \mathrm{X}$, Dockery DW, Ware JH, et al. Effects of cigarette smoking on rate of loss of pulmonary function in adults: a longitudinal assessment. Am Rev Respir Dis 1992;146: $1345-8$

26 Marine WM, Gurr D, Jacobsen M. Clinically important respiratory effects of dust exposure and smoking in British coalminers. Am Rev Respir Dis 1988;137:106-12.

27 Dockery DW, Pope CA. Acute respiratory effects of particulate air pollution. Annu Rev Public Health 1994;15:107-32.

28 Bakke B, Ulvestad B, Stewart P, et al. Exposure and short-term lung function changes in tunnel construction workers: effects of blasting fumes and diesel exhaust. Scand $\mathcal{F}$ Work Environ Health 2001 (in press).

29 Kessel R, Redl M, Mauermayer R, et al. Changes in lung function after working with the shotcrete lining method under compressed air conditions. Br F Ind Med 1989;461: 28-32.

30 Bhatia R, Lopipero P, Smith AH. Diesel exhaust exposure and lung cancer. Epidemiol 1998;9:84-91.

31 Wade JF, Newman LS. Diesel asthma: reactive airways disease following overexposure to locomotive exhaust. f Occup Environ Med 1993;35:149-55.

32 Mauderly JL. Toxicological and epidemiologic evidence for health risks from inhaled engine emissions. Environ Health Perspect 1994;102:165-71.

33 Stanevich RS, Hintz P, Yereb D, et al. Elemental carbon levels at a potash mine. Appl Occup Environ Hyg 1997;12: 1009-12.

\section{Correspondence and editorials}

Occupational and Environmental Medicine welcomes correspondence relating to any of the material appearing in the journal. Results from preliminary or small scale studies may also be published in the correspondence column if this seems appropriate. Letters should be not more than 500 words in length and contain a minimum of references. Tables and figures should be kept to an absolute minimum. Letters are accepted on the understanding that they be subject to editorial revision and shortening.

The journal also publishes editorials which are normally specially commissioned. The Editor welcomes suggestions regarding suitable topics; those wishing to submit an editorial, however, should do so only after discussion with the Editor. 